\title{
Evaluation of pregnancy outcome and influencing factors of microsurgical tubal recanalization as a reversal of tubal ligation in a tertiary hospital
}

\author{
Animesh Naskar ${ }^{1}$, Somasree Gharami ${ }^{2}$, Aparna Khan Mandal ${ }^{3}$, Bharat Chandra Mandi ${ }^{4}$, \\ Rupkamal Das 5
}

${ }^{1}$ Associate Professor, ${ }^{2}$ Senior Resident, ${ }^{3}$ Associate Professor, ${ }^{4}$ Clinical Tutor, ${ }^{5}$ Professor, Department of Obstetrics and Gynaecology, R. G. Kar Medical College and Hospital, Kolkata, West Bengal, India

A B S T R A C T

Background: Tubal microsurgical recanalization is a procedure which restores the fertility in women who have undergone sterilization voluntarily, thinking that her family is complete. However due to unforeseen circumstances, 1-3\% of these women subsequently demand reversal of sterilization. Aims and Objectives: This study aims to evaluate the pregnancy rate after reversal surgery and to find out the various factors that influence the success of tubal microsurgical recanalization. Materials and Methods: The current study was hospital-based retrospective one involving 48 women undergoing reversal of sterilization at the department of gynecology and obstetrics in tertiary hospital, Kolkata, during the period of 3 years, from July 2015 to June 2018. The women were followed up for a period of 1 year by telephonic contact. Women seeking tubal recanalization was in age group of 20-35 years with normal ovulation and normal semen analysis. Women, $>35$ years old, anovulation, with obvious pelvic inflammatory disease, endometriosis or fibroid were excluded, women with any contraindications to pregnancy or surgery and any male factor infertility also excluded from the study. Results: Out of 48 study subjects, intrauterine pregnancy was achieved in 27 cases $(93.1 \%)), 2$ patients $(6.9 \%)$ had ectopic pregnancy. Out of 27 intrauterine pregnancies, 4 had abortions $(13.8 \%), 3(10.3 \%)$ are ongoing pregnancies, and 20 patients had live birth $(69 \%)$. Conclusion: Tubal microsurgery offers good chances of pregnancy outcome which is favored by the age below 30 years, interval between sterilization and its reversal $<4$ years, isthmo-isthmic anastomosis, reconstructed tubal length being more than $6 \mathrm{~cm}$, and type of previous sterilization were by Pomeroy's method.

Key words: Microsurgery; Pregnancy; Reversal; Sterilization; Tubal length; Tubal recanalization

\section{INTRODUCTION}

Tubectomy, an integral part of national family planning program of India, is one of the most acceptable methods of female contraception among women of reproductive age. In India, female sterilization is accounted for $36 \%$ of all methods of family planning practiced in our country according to NFHS-4 (2015-2016). ${ }^{1}$ However, about 10\% of them later regret their decision due to unavoidable
Website:

http://nepjol.info/index.php/AJMS DOI: 10.3126/ajms.v13i2.40450

E-ISSN: 2091-0576

P-ISSN: 2467-9100

Copyright (c) 2022 Asian Journal of Medical Sciences

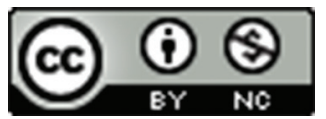

This work is licensed under a Creative Commons Attribution-NonCommercial 4.0 International License.

Address for Correspondence:

Dr. Animesh Naskar, Associate Professor, Department of Obstetrics and Gynaecology R. G. Kar Medical College and Hospital, Kolkata,

West Bengal, India. Mobile: 8240635615. E-mail: animesh282@gmail.com 
high cost of it, most women opt for microsurgical tubal recanalization. ${ }^{3}$ Although laparoscopic recanalization has taken over conventional open microsurgical technique in west, because of cost and technical expertise involved in this procedure, laparoscopic technique remains available to very few reversal seeking women in India and can be adopted as alternative to tubal microsurgical technique through laparotomy. ${ }^{4}$ Popularity in the new microsurgical techniques in reversal of sterilization is mostly due to associated improvement in the success in pregnancy rate in comparison to traditional surgical techniques. Several factors such as the age of the women, type of tubectomy done, duration since tubectomy and remaining length of the tube after reversal operation, and techniques of recanalization have been considered to influence the outcome of recanalization. The present study aimed to find out the conception rate and the factors which can affect the successful pregnancy outcome following tubal recanalization.

\section{Aims and objectives}

To find out the pregnancy rate following tubal recanalisation and the factors which can affect the success of microsurgical reversal following tubal ligation.

\section{MATERIALS AND METHODS}

This was a hospital-based retrospective study of 48 women, aged 20-35 years, underwent tubal recanalization, in the Department of Obstetrics and Gynaecology of R G Kar Medical College and Hospital, Kolkata, for a period of 3 years, from July 2015 to June 2018. Approval of the Institutional Ethical committee was obtained. All the study women were followed up for a period of 1 year. Inclusion criteria of our study were patient having tubal block due to sterilization (laparoscopic or open method), normal ovulatory function (patient presenting with regular menstrual cycle), and husband's normal semen analysis. Exclusion criteria were pelvic pathology or any congenital uterine anomalies or severe endometriosis or pelvic inflammatory disease, anovulatory infertility, female with bilateral hydrosalpinx or totally distorted bilateral tube as diagnosed by hysterosalpingography or laparoscopy, any male factor for infertility, and remnant length of the fallopian tubes $<4 \mathrm{~cm}$ as seen in HSG or by laparoscopy.

\section{Sample size}

According to study conducted by Jayakrishnan and Beheti, $85.7 \%$ conceived following laparoscopic recanalization in cases with sterilization by laparoscopic method of tubal ligation..$^{5}$

Taking this proportion, the sample size was calculated using this formula:

$$
\begin{aligned}
& \mathrm{n}=\mathrm{z}^{2} \mathrm{p}(1-\mathrm{p}) / \mathrm{d}^{2} \\
& \mathrm{n}=\text { sample size } \\
& \mathrm{z}=1.96 \text { for } 95 \% \text { confidence limit } \\
& \mathrm{p}=\text { anticipated proportion }=85.7 \% \\
& \mathrm{~d}=\text { Acceptable margin of error }=10 \% \mathrm{n}=(1.96)^{2} \times 85.7 \times \\
& (100-85.7) / 10^{2} \\
& =47.07 \sim 48
\end{aligned}
$$

Overall, it was estimated that 48 women will have to be recruited for the purpose of our study.

\section{Data collection and procedure}

Over the period of study, women were enrolled as per the inclusion and exclusion criteria. Data collected by reviewing records and they were followed up over telephonic conversations. Data collection was started from August 2019 and the procedure was continued till February 2020. Topic and objective of the study were clearly explained to each study subjects and informed consent was taken. The participants were assured of the confidentiality. An interview was conducted using a pre-designed pretested semi-structured questionnaire focusing on details of sterilization, including the age at the time of sterilization, parity at the time of sterilization, type of sterilization, interval between sterilization and reversal, and reason for reversal of sterilization.

Obstetrics history including parity and the cause for death of child if any was recorded. Their laboratory investigation details both before and after recanalization taken from hospital records and reports from patients.

Details of recanalization procedure including site of anastomosis, suture material used, adhesion preventing drugs used, post-operative period; post-operative assessment of tubes, ovaries and uterus by both HSG and laparoscopy, any supplementary treatment as example hydrotubation, ovulation induction, metformin needed or not, recorded from records of hospital, and patients records.

Outcome of recanalization in terms of pregnancy and outcome of pregnancy (live birth, abortion, IUFD, ongoing pregnancy, and ectopic pregnancy) was recorded.

\section{Microsurgical technique}

Tubal recanalization by microsurgical technique was carried out in the postmenstrual phase. A Pfannenstiel incision was given and the findings such as endometriosis and PID if present were noted. Under magnification with microsurgical instruments and constant irrigation with normal saline, tubectomized sites were freshened. Anastomosis was done by 6-0 Vicryl suture materials for suturing muscularis layer. First bite was taken at 6-O clock position that is mesenteric border and later 3, 9, and 12-O 
clock positions. Serosa was approximated similarly. Patency of both ends was established by direct tube testing by injecting methylene blue dye. For fimbriectomy cases, cuff salpingostomy was done. Perfect hemostasis was achieved using bipolar cautery. Tubal length was noted at the end of the surgery. Hydroflotation was done with normal saline.

The parameters studied were condition of the tubes, ovaries, uterus, and type of tubectomy, anatomical site of anastomosis, final length of the reconstructed tube, and the use of adjuvant therapy such as adhesion preventing drugs and irrigation fluids. Prophylactic antibiotics coverage (inj. ciprofloxacin and inj. metronidazole) was used. In all cases, inj. promethazine (Phenergan) $25 \mathrm{mg}$ i.m. $8^{\text {th }}$ hourly was given for 5 days with or without inj. dexamethasone. Any complication, if present, were recorded.

Women were discharged after removal of skin suture and were advised regarding utilization of the fertile period and risk of ectopic pregnancy and to start sexual activity after 2 months. They were followed for a period of 1 year and events such as pregnancy, ectopic pregnancy, and pelvic infection were recorded. If there was no conception within 1 year, hysterosalpingogram was done to check for tubal patency.

\section{Statistical analysis}

The data were compiled using Statistical Package for the Social Sciences (SPSS) for Windows (SPSS, Inc., Chicago, IL, USA). Various coding had given to variable and then data recorded for analysis. By proportion and frequency, categorical data were presented. For qualitative data, Chisquare test was used as a test of significance; $\mathrm{P}<0.05$ was considered to be statistically significant.

\section{RESULTS}

Out of 48 study subjects, $50 \%$ were in the age group of 26-29 years followed by $33.3 \%$ were in the age group of $30-35$ years and $16.7 \%$ were in the age group of below 25 years (Table 1$)$. The mean age of the participants was $28.63 \pm 3.22$ years with a median of 28 years and range of 23-35 years. Most of the women (54.2\%) were having parity 2 or less than that and $56.3 \%$ of women underwent sterilization by Pomeroy's method. Most of the study subjects (45.80\%) underwent sterilization concurrent with LSCS followed by interval ligation in $25 \%$ of patients. Frequency of puerperal ligation and postabortal ligation was same $(14.6 \%)$. Common reasons seeking recanalization in the study were either death of all children (47.9\%) or demise of 1 child (22.9\%). In our study, $60.4 \%$ of women conceived out of which 69\% live birth, $13.8 \%$ abortion, and ectopic pregnancy $6.9 \%$ and ongoing pregnancy was $10.3 \%$ (Table 2). In this study, association between sterilization- recanalization interval $<4$ years and conception rate after recanalization was statistically significant with P-value 0.05 (Table 3). Remarkable conception $(55.2 \%)$ was achieved in the age group of 26-29 years, in our study. Association between length of reconstructed tube and conception rate after recanalization was remarkable. The study showed that if the reconstructed tube length is $>6 \mathrm{~cm}$, conception rate is highest $68.15 \%$ (Table 4 ). It was seen that isthmoisthmic anastomosis associated with higher pregnancy rate (70.55\%) followed by isthmo-ampullary (57.25\%). Most of the tubes (bilaterally) which were found healthy conceived $(67.95 \%)$. Most of the cases conceived that there was no peritubal adhesion $(62.45 \%)$. In $69.7 \%$ of cases, there was good spillage of dye in HSG, and they conceived. Uterine anomaly was noted in three cases, where pregnancy rate was $66.7 \%$.

\begin{tabular}{|c|c|c|}
\hline $\begin{array}{l}\text { Factors affecting outcome of } \\
\text { recanalization }\end{array}$ & $\begin{array}{l}\text { Frequency } \\
(n=48)\end{array}$ & Percentage \\
\hline \multicolumn{3}{|l|}{ Age group } \\
\hline Up to 25 & 8 & 16.7 \\
\hline $26-29$ & 24 & 50.0 \\
\hline $30-35$ & 16 & 33.3 \\
\hline \multicolumn{3}{|l|}{ Parity } \\
\hline 2 or less & 26 & 54.2 \\
\hline 3 or more & 22 & 45.8 \\
\hline \multicolumn{3}{|l|}{ Age of ligation } \\
\hline Up to 19 & 14 & 29.2 \\
\hline $20-25$ & 29 & 60.4 \\
\hline $26-30$ & 5 & 10.4 \\
\hline \multicolumn{3}{|l|}{ Method of ligation } \\
\hline Pomeroy's method & 27 & 56.3 \\
\hline Laparoscopic & 17 & 35.4 \\
\hline \multicolumn{3}{|l|}{ Method (Falope ring) } \\
\hline Fimbriectomy & 4 & 8.3 \\
\hline \multicolumn{3}{|l|}{ Site of ligation } \\
\hline Ampullary & 18 & 37.5 \\
\hline Isthmic & 23 & 47.9 \\
\hline Fimbriectomy & 7 & 14.6 \\
\hline \multicolumn{3}{|l|}{ Length of reconstructed tube } \\
\hline$>6 \mathrm{~cm}$ & 26.5 & 55.2 \\
\hline $4-6 \mathrm{~cm}$ & 21 & 43.75 \\
\hline$<4 \mathrm{~cm}$ & 0.5 & 1.05 \\
\hline \multicolumn{3}{|l|}{ Sterilization-recanalization interval } \\
\hline$<4$ years & 2 & 4.2 \\
\hline $4-6$ years & 31 & 64.6 \\
\hline$>6$ years & 15 & 31.3 \\
\hline
\end{tabular}

\begin{tabular}{lcc}
$\begin{array}{l}\text { Table 2: Pregnancy outcome of tubal } \\
\text { microsurgery }\end{array}$ & \\
\hline $\begin{array}{lcc}\text { Outcome of } \\
\text { recanalization }\end{array}$ & $\begin{array}{c}\text { Frequency } \\
\text { (No.=48) }\end{array}$ & Percentage \\
\hline A. Conceived & 29 & 60.4 \\
Live birth & 20 & 69.0 \\
Abortion & 4 & 13.8 \\
Ongoing pregnancy & 3 & 10.3 \\
Ectopic pregnancy & 2 & 6.9 \\
B. Not conceived & 19 & 39.6 \\
\hline
\end{tabular}




\begin{tabular}{|c|c|c|c|}
\hline \multirow[t]{2}{*}{ Determinants } & \multicolumn{2}{|c|}{ Outcome of recanalization } & \multirow{2}{*}{$\begin{array}{c}\text { Chi-square value df } \\
\text { P value }\end{array}$} \\
\hline & Conceived $(n=29)$ & Not conceived $(n=19)$ & \\
\hline \multicolumn{4}{|l|}{ Age group } \\
\hline Up to 25 & $5(17.2)$ & $3(15.8)$ & 1.132 \\
\hline $26-29$ & $16(55.2)$ & $8(42.1)$ & 2 \\
\hline 30-35 & $8(27.6)$ & $8(42.1)$ & 0.577 \\
\hline \multicolumn{4}{|l|}{ Method of ligation } \\
\hline Pomeroy's method & $15(51.7)$ & $9(31.0)$ & 0.753 \\
\hline Laparoscopic method (Falope ring) & $11(37.9)$ & $14(48.3)$ & 2 \\
\hline Fimbriectomy & $3(10.3)$ & $6(20.7)$ & 0.743 \\
\hline \multicolumn{4}{|l|}{ Site of ligation } \\
\hline Ampullary & $9(31.0)$ & $9(47.4)$ & 2.692 \\
\hline Isthmic & $14(48.3)$ & $9(47.4)$ & 2 \\
\hline Fimbriectomy & $6(20.7)$ & $1(5.3)$ & 0.690 \\
\hline \multicolumn{4}{|l|}{ Sterilization-recanalization interval } \\
\hline$<4$ years & $2(100.0)$ & $0(0.0)$ & 10.915 \\
\hline $4-6$ years & $23(74.2)$ & $8(25.8)$ & 2 \\
\hline$>6$ years & $4(26.7)$ & $11(73.3)$ & $0.004^{*}$ \\
\hline
\end{tabular}

\begin{tabular}{|c|c|c|c|}
\hline \multirow{2}{*}{$\begin{array}{l}\text { Length of } \\
\text { reconstructed } \\
\text { tube }\end{array}$} & \multicolumn{2}{|c|}{ Outcome of recanalization } & \multirow{2}{*}{$\begin{array}{l}\text { Chi-square } \\
\text { value df } \\
\text { P-value }\end{array}$} \\
\hline & $\begin{array}{c}\text { Conceived, } \\
\text { n (\%) }\end{array}$ & $\begin{array}{l}\text { Not conceived, } \\
\mathrm{n}(\%)\end{array}$ & \\
\hline \multicolumn{4}{|l|}{ Left } \\
\hline$>6$ & $18(72 \%)$ & $7(28 \%)$ & $\begin{array}{c}2.927 \\
1\end{array}$ \\
\hline $4-6$ & $11(47.8 \%)$ & $12(52.2 \%)$ & 0.087 \\
\hline \multicolumn{4}{|l|}{ Right } \\
\hline$>6$ & $18(64.3 \%)$ & $10(35.7 \%)$ & 1.752 \\
\hline $4-6$ & $11(57.9 \%)$ & $8(42.1 \%)$ & 2 \\
\hline$<4$ & $0(0 \%)$ & $1(100 \%)$ & 0.456 \\
\hline
\end{tabular}

\section{DISCUSSION}

There are multiple factors that determine the outcome of tubal recanalization surgery by microsurgical technique. In our study, majority of women (50\%) were in the age group of 26-29 years which correspond with the study of Biswas and Mondal where $50.8 \%$ was in this age group. ${ }^{6}$ Age has a definite effect on pregnancy rate. A higher conception rate $(68 \%)$ in younger age group ( $20-30$ years) may be attributed to their greater fertility potential as shown in the study by Brar et al., Jain et al., showed a higher pregnancy rate $(75 \%)$ when the age of the patient was $<25$ years. ${ }^{8}$ Cohen et al., ${ }^{9}$ performed a multicenter retrospective study and observed pregnancy rates which were significantly lower in women aged 40 compared to younger groups.

In our study, most reversal seekers $(54.2 \%)$ were para two or less. This high figure of low parity coincides with the study of Maya et al., in which $54.5 \%$ of women were para two. ${ }^{10}$ The method of previous tubal sterilization used, is an important determining factor for success of sterilization reversal. Biswas and Mondal found that $59.65 \%$ of women had previous laparoscopic sterilization. ${ }^{6}$ In our study, 35.4\% had laparoscopic sterilization and the rest had undergone Pomeroy's type of sterilization. The present study showed a success rate of $56.3 \%$ in women who had undergone Pomeroy's method of sterilization as compared to $35.4 \%$ in women following reversal of laparoscopic technique. In a prospective study by Maya et al., $90.9 \%$ had undergone minilaparotomy using modified Pomeroy technique. ${ }^{10}$ Success rate in this study following minilaparotomy was $35 \%$.

In the present study, death of one or all children was the most common reason for couple to seek reversal of sterilization (70.8\%). A study by Mukherjee et al., ${ }^{11}$ showed that death of all children was the most common reason $(91.8 \%)$ for reversal of sterilization, which coincides with the study by Jain et al., where $70 \%$ of women sought reversal for death of all children. This observation is in contrast to Western countries where the most common indication was remarriage or divorce seen in $80-90 \%$ of the cases as per Grunert et al. ${ }^{12}$ Biswas and Mondal opined that death of a male child (53.5\%) in a male dominated society makes the couple to try once more and solicit a sterilization reversal. ${ }^{6}$ In the study by Promila et al., death of a male child $(64.2 \%)$ was the major reason for sterilization reversal. ${ }^{13}$

In the present study, $31.3 \%$ of women had undergone sterilization more than 6 years ago, but a higher pregnancy rate $(100 \%)$ has been reported when the interval between sterilization and reversal operation is $<4$ years. Biswas and Mondal showed in their study that $50 \%$ of women came for sterilization reversal within 3 years of sterilization. ${ }^{6}$ In a study by Brar et al., pregnancy rate was $100 \%$ when the interval was $<2$ years. ${ }^{7}$ Kalaichelvi et al., found that $87 \%$ of women conceived when recanalization was done within 
1 year of sterilization while the incidence dropped to $16 \%$ when the interval was more than 10 years. ${ }^{14}$

In the present study, the most common site of anastomosis was isthmo-isthmic (42.7\%) followed by isthmo-ampullary $(27.1 \%)$ and the least was cuff salpingostomy (7.3\%), which coincides with studies by Brar et al., 7 and Biswas and Mondal where the most common type of anastomosis was isthmo-isthmic in $48 \%$ and $49.1 \%$, respectively. ${ }^{6}$

In the present study, bilateral isthmo-isthmic anastomosis resulted in pregnancies in $70.5 \%$ of women, bilateral isthmo-ampullary in $57.25 \%$, and bilateral ampulloampullary in $47.2 \%$. Maya et al., in a prospective analysis of 22 women who underwent microsurgical tubal reversal, found that $75 \%$ conceived after isthmo-isthmic anastomosis, $33.3 \%$ after isthmo-ampullary anastomosis, and none after ampullo-ampullary anastomosis. ${ }^{10}$ In a study by Kalaichelvi et al., $76.2 \%$ of intrauterine pregnancies were seen in women who had isthmo-isthmic anastomosis while the highest incidence of tubal pregnancies $(7.4 \%)$ occurred in the isthmo-cornual anastomosis. ${ }^{14}$ In a study by Promila et al., $80 \%$ of term pregnancies occurred after bilateral isthmo-isthmic anastomosis but only $50 \%$ of term pregnancies after bilateral isthmo-ampullary anastomosis. ${ }^{13}$

The most important factor to enhance the effectiveness of recanalization is the length of the reconstructed tubes Silber and Cohen. ${ }^{15}$ In the present study, $98.95 \%$ had final tubal length of more than $4 \mathrm{~cm}$. The pregnancy was achieved in $68.15 \%$ of the women when the tubal length was more than $6 \mathrm{~cm}$ in comparison to $47.85 \%$ when the length was $4-6 \mathrm{~cm}$.

Jain et al., confirmed the importance of tubal length in terms of live birth rates by their prospective study. ${ }^{8}$ When length of tube was more than $8 \mathrm{~cm}$, the pregnancy rate was $83.33 \%$ which was markedly reduced to $4 \%$, if length of tube was $<4 \mathrm{~cm}$. In a prospective study by Maya et al., with a reconstructed tubal length of more than $8 \mathrm{~cm}$, the pregnancy rate was $100 \%$ while with a tubal length ranging from $4 \mathrm{~cm}$ to $8 \mathrm{~cm}$, the pregnancy rate was $53.3 \%$. None conceived with tubal length $<4 \mathrm{~cm} .{ }^{10}$

The current study showed that the overall conception rate was $60.4 \%$ (29 cases) out of which 27 cases $(93.1 \%$ ) were intrauterine pregnancies; 2 (6.9\%) had ectopic pregnancy, live birth was $69 \%$ (20 cases), and abortion rate was $13.8 \%$. In our study, $90.5 \%$ conceived within 12 months of reversal of sterilization. In a similar study, Brar et al., ${ }^{7}$ showed $68 \%$ intrauterine pregnancy and in a study of Biswas and Mondal showed intrauterine pregnancy rate of $66.27 \% .{ }^{6}$ In a retrospective study by Yadav et al., ${ }^{16}$ the overall conception rate was $68 \%$, out of which intrauterine pregnancy rate was
$62 \%$, ectopic pregnancy rate was $6 \%$, and the abortion rate was $6 \%$. Fifty percent of patients conceived within the first 12 months of reversal of sterilization.

In the present study, out of 48 women, 19 women had not conceived by the end of 1 year, bilateral tubal patency was assessed by hysterosalpingography. Bilateral tubal patency was established in 52.6\% (10 cases); unilateral tubal patency was seen in $42.1 \%$ ( 8 cases), and bilateral tubal block in $5.3 \%$ (1 case). Out of those women with patent fallopian tube, two women were not staying with their partner, two women were not interested in conception, and five women were having anovulatory cycles following reversal of sterilization. Rest of the women are undergoing ovulation induction and are under regular follow-up.

\section{Limitations of the study}

It may be noted that our follow-up period was limited and although pregnancies were spontaneous, some interventions such as hydrotubation and ovulation induction were done to improve the conception rate during the study period. Skill and expertization of the surgeon can influence the outcome which is not included here as well as effectivity of dexamethasone peroperatively has not proven.

\section{CONCLUSION}

Although tubal microsurgical reversal offers better pregnancy rate in our study, certain important factors such as age of the patient $<30$ years, the interval between sterilization and its reversal $<4$ years, isthmo-isthmic anastomosis, the reconstructed tubal length $>6 \mathrm{~cm}$, and previous sterilization by Pomeroy's method played a determining role to achieve successful pregnancy. Since every patient undergoing sterilization is a potential candidate for reversal, we propose that every effort should be made to perform sterilization over isthmus, keeping maximum length of the tube which may bring a ray of hope to hopeless.

\section{ACKNOWLEDGMENT}

We would like to thank all the women participated in this study and all concerned staffs in the Department of Gynaecology and Obstetrics, R G Kar Medical College for their cooperation.

\section{REFERENCES}

1. India Fact Sheet R10: NFHS (NFHS 4). NFHS; 2015-2016. p. 3-8.

2. Hanafi M. Factors affecting the pregnancy rate after microsurgical reversal of tubal ligation. Fertil Steril. 2003;80(2):432-440. https://doi.org/10.1016/S0015-0282(03)00661-7 
3. Shilpa MN, Shivanna BS and Gopal N. Correlation of prognostic factors and outcome of microsurgical tubal recanalization. IOSR J Dent Med Sci. 2014;13(9):13-15.

4. Navy MJ. Tubal surgery or IVF-making the best choice in the 1990s. Int J Fertil. 1995;40(6):291-302.

5. Jayakrishnan $\mathrm{K}$ and Baheti SN. Laparoscopic tubal sterilization reversal and fertility outcome. J Hum Reprod Sci 2012;4(3):125-129.

http://doi.org/10.4103/0974-1208.92286

6. Biswas A and Mondal A. Evaluation of women undergoing sterilization reversal and subsequent pregnancy outcome. J Ind Med Assoc. 2006;104(4):182-185.

7. Brar MK, Jaswinder and Kaur S. A study of microsurgical reanastomosis of the fallopian tubes for reversal of sterilization. J Obstet Gynecol Ind. 2000;50:75-77.

8. Jain M, Jain P, Garg R and Tripathi FM. Microsurgical tubal recanalization: A hope for the hopeless. Indian J Plast Surg. 2003;36:66-70.

9. Cohen MA, Chang PL, Uhler M, Legro R, Sauer MV and Lindheim SR. Reproductive outcome after sterilization reversal in women of advanced reproductive age: J Assist Reprod and Genet. 1999;16(8):402-404.

http://doi.org/10.1023/a1020509323039
10. Maya P, Prasad PH, Kumar MS and Kumar MS. Microsurgical reversal of sterilization a 5 year analysis J Obstet Gynecol Ind. 2003;53(5):473-474

11. Mukherjee GG, Majhi AK and Jana SK. Evaluation of women seeking sterilization reversal. J Indian Med Assoc. 2000;98:163-5.

12. Grunert GM, Drake TS and Takaki NK. Microsurgical reanastomosis of the fallopian tubes for reversalof sterilization. Obstet Gynaecol. 1981;58(2):148-151.

13. Promila J, Kaur GB and Shweta G. Reversal of tubal ligation under $4 \mathrm{x}$ magnification. J Obstet Gynecol Ind. 2005;55:448-450.

14. Kalaichelvi A, Swarnalatha $R$ and Premlatha R. Is reversal of sterilization feasible? J Obstet Gynecol Ind. 2001;51(2):120-122. http://doi.org/10.1007/s13224-012-0144-x

15. Silber SJ and Cohen R. Microsurgical reversal of tubal sterilization: factors affecting pregnancy rate, with long-term follow-up. Obstet Gynaecol. 1984;64(5):679-682.

16. Yadav R, Reddi $R$ and Bupathy $A$. Fertility outcome after reversal of sterilization. J Obstet Gynecol Res. 1998;24(6):393-400.

http://doi.org/10.1111/j.1447-0756.1998.tb00114.x

Authors Contribution:

AN- Concept and design of the study, prepared first draft of manuscript, and revision of manuscript; SG- Data collection, interpreted the results, review of literature, and manuscript preparation; AKM- Coordination and preparation of manuscript; BCM- Coordination and support; and RD- Concept of study and revision of manuscript.

Work attributed to:

R. G. Kar Medical College and Hospital, Kolkata, West Bengal, India

Orcid ID:

Dr. Animesh Naskar - (i) https://orcid.org/0000-0002-9319-6465

Dr. Somasree Gharami - (D) https://orcid.org/0000-0003-2271-2466

Dr. Rupkamal Das - (D) https://orcid.org/0000-0003-2084-9055

Dr. Bharat Chandra Mandi - (D https://orcid.org/0000-0002-0899-640X

Source of Funding: None, Conflicts of Interest: None. 